\title{
Field-testing PBL Approach Seeking Web-based Distance Education Applications
}

\author{
Perez, D. ${ }^{1}$; Yokaichiya, D. K. ${ }^{1}$; Galembeck, E. ${ }^{1}$.
}

${ }^{1}$ Depto. de Bioquímica, IB, Unicamp, SP. email: perez@unicamp.br

Problem Based Learning (PBL) approach has been worldwide used in medical education and it is also been implemented in other fields such as science, technology and mathematics education. PBL is also a collaborative learning approach such as the small group study techniques that has been widely used in the biochemistry classes at Universidade Estadual de Campinas (Unicamp).

This study aims to design and to field-test a PBL approach on Free Radicals to be used in a distance education course. We developed a problem and field-tested it in two regular biochemistry courses: BB280 (Biochemistry to Biology) and BB591 (Biochemistry to Engineering). The students were organized in groups from 8 to 10 components. The results collected from each group during their meetings and from the evaluation sheets were used to understand if the problem was well designed and if it could be successfully used in a face-to-face course, before being adapted to a Web-based distance course.

The results suggested that the tested problem could be used to reach the desired skills on a Free Radicals class at undergraduate level. The evaluation also suggests that the learning issues are reachable and that the problem designed is simple, objective, and strongly stimulating, both in the tutorial group discussion and in the individually self-directed study.

Since the problem can be used to reach the learning issues in a face-to-face situation, it will be them adapted to a distance education course on Nutritional Biochemistry.

Supported by: CAPES 